\title{
Treatment of Residual Pain After Total Knee Arthroplasty
}

\author{
Renato Luiz Bevilacqua De Castro, Breno Pazinatto Antonio*, Gustavo Concon de Castro, and \\ Fernanda Dutra Santiago Bassora \\ Center for Studies on Tissue Regeneration - CERT, Brazil
}

*Corresponding author: Breno Pazinatto Antonio, Center for Studies on Tissue Regeneration, Avenida Barão de Itapura, 3378,

Taquaral, Campinas, SP, Brazil

\begin{abstract}
ARTICLE INFO
Received: 幽 October 22, 2019

Published: 幽 October 31, 2019

Citation: Renato Luiz Bevilacqua De C, Breno Pazinatto A, Gustavo Concon de C, Fernanda Dutra Santiago B. Treatment of Residual Pain After Total Knee Arthroplasty. Biomed J Sci \& Tech Res 22(3)-2019. BJSTR. MS.ID.003746.
\end{abstract}

Keywords: Total knee Arthroplasty; Residual Pain; Non-Operative Treatment; Knee Pain; Knee Function

\begin{abstract}
Currently, total knee arthroplasty (TKA) is a well-established surgery in medical practice, with a high degree of success. However, recent studies have reported that many patients show dissatisfaction, including residual pain and limited function, even after TKA without evident clinical or radiological findings. Understanding the causes of the residual pain by a systematic approach is essential to its treatment and, in some cases, revision surgery is mandatory. Once the eminent surgical indications were excluded, we performed the non-operative treatment. The goal of the treatment is to decrease pain and improve knee function. Periarticular injections and nerve blocks are gaining popularity for being effective, with low adverse effects. The use of pain medications should be carefully indicated as a support, and the advantages should be evaluated individually.
\end{abstract}

Abbreviations: TKA: Total Knee Arthroplasty; PCS: Pain Catastrophizing Scale; PRP: Platelet Rich Plasma; PNB: Peripheral Nerve Blocks; FNB: Femoral Nerve Block; ACB: Adductor Canal Blockage; GNB: Genicular Nerve Blocks; RCT: Randomized Controlled Trail

\section{Introduction}

Currently, Total Knee Arthroplasty (TKA) is a well-established surgery in medical practice, with a high degree of success. TKA is indicated in cases of severe knee osteoarthritis that had no success with conservative non-surgical treatment, in patients without contraindications to surgical treatment, who are aware of and agree with the risks inherent to the surgery. The literature demonstrates that TKA is capable of improving knee pain, function and deformities in the last stage of osteoarthritis [1,2], but complications are not uncommon. Rozell investigated a group of 802 patients who underwent TKA and hip arthroplasty and found that 382 patients had postoperative complications [3]. The level of satisfaction with the results of the surgery is not high, with dissatisfaction reaching levels higher than 50\% [4-8]. Considering that the absolute and relative numbers of TKAs in society is increasing, and that the population is growing continuously, associated with an increase in longevity, metabolic syndrome and joint diseases, it is expected that the number of complications and unsatisfactory results in TKA tend to essential in the conduction of the patient with residual pain after TKA. A review of the surgery without the proper diagnosis, in most cases leads to persistence of pain or case worsening [9]. The diagnosis of residual pain after arthroplasty, its surgical indications, and especially indications and non-operative treatments will be discussed in this paper.

\section{Diagnosis and Pathogenesis of Residual Pain After Total Knee Arthroplasty}

There are many causes of residual pain after TKA, and the literature classifies the symptoms in several ways, mainly as: (a) articular and extra-articular and (b) infectious and non-infectious. The focus of this review is to determine which diagnoses indicate a revision surgery or other surgical procedure, and those (that appear to be the overwhelming majority) which will be treated with interventional techniques for pain and regenerative medicine. The most important for the elucidation of the cause of pain in these patients is to initially listen carefully to the complaint, the detailed history of the characteristics of the pain, the factors of worsening and improvement, the time of evolution, the treatments 
already performed and, especially, how limiting the pain is. At this stage of the anamnesis, we suggest the use of a numerical pain scale for future follow-upand for measuring the importance of the pain. Personal and family history are also important, and this set of data alone often provides the clinician with a narrow picture of diagnostic hypotheses.

Static physical examination with the patient standing, if possible, will show alignment, deformities in flexion and recurvatum, edema, hyperemia, visualization of the scar, fistulas or wounds. In the dynamic examination, the knee's temperature is checked, as well as, the effusion test, palpation of painful stitches with penmarking for ultrasonographic examination, passive and active flexion-extension, ligament stress and examination of the other joints, especially the lumbar sacral spine and hip. After physical examination, we routinely perform an ultrasound examination of the joint to diagnose bone and prosthesis prominences that may cause pain, especially points already marked with pen on physical examination, synovitis, joint effusion, patella height, patellar and quadriceps tendon integrity, cysts research, examination of the popliteal artery and vein and dynamic examination to show loosening of the tibial, femoral or patellar components.

\section{When the Surgical Revision Is Mandatory}

The failure of a TKA, especially if the surgery is recent, is usually caused by ascetic release, infection or instability. For a surgeon who is accustomed to the classical signs of this condition, the diagnosis is relatively straightforward. However, for a pain doctor, a special attention is needed, so as not to treat clinically a condition that is eminently surgical. In cases of release by infection, the prosthesis is removed and a spacer with cement and antibiotics is left as a "protector" of the knee for the healing period of the infection by cleaning and antibiotic therapy. After the identification of the pathogen, the assistance of an infectious disease doctor is always welcome. Once the infection has been cleared, the spacer is removed, and a new prosthesis is implanted $[10,11]$.

\section{Allergy to Metal}

Hypersensitivity to metals affects approximately $10 \%$ of the population, mainly people who have daily exposure to metals $[12,13]$. Therefore, it is very important to investigate allergies to metals in the anamnesis. Nickel allergy is the easiest to identify. Chromium and cobalt allergies are the most difficult ones to be identified. They can be tested on specific exam, although dermal tests have high sensitivity but low specificity, and the skin response may not be the same as synovial tissue, which is especially very immunologically reactive [14]. The diagnosis of metal allergy is especially difficult. Some recent "in vitro" tests such as the lymphocyte transformation test, evaluation of cytokine concentration with ELISA and migration inhibitory factor, are still under academic discussion about the " in vivo" reproducibility [15]. In the clinical evaluation of patients suspected of metal hypersensitivity, we observed persistent and symptomatic effusion and synovitis, pruritus in different parts of the body and impaired joint function. Medicinal treatments usually have no effect, and usually revision with an antiallergic prosthesis is the solution. Currently, there are prostheses with less allergenic power such as zirconium and ceramics.

\section{Other Synovitis}

In the differential diagnosis of synovitis due to hypersensitivity to the metal, magnetic resonance and synovial fluid examination are common tools in the diagnosis of gout, chondrocalcinosis, polyethylene debris, rheumatoid arthritis and infection. Magnetic resonance imaging can show typical images with a high degree of specificity, and in case of release of the prosthesis by polyethylene debris, a frondlike image is a strong indication of the pathology $[16,17]$. Another common cause of synovitis after TKA is chondrocalcinosis. The incidence of deposition of calcium pyrophosphate crystals in knee prostheses reaches $60 \%$ in some series. In magnetic resonance imaging, the image will be of non-specific synovitis, however, the investigation of crystals in the aspirated liquid of the knee will be weakly positive, when birefringence is examined, and the crystals of urate will be negative [18].

\section{Complex Regional Pain Syndrome}

The complex regional pain syndrome is a sympathetic or parasympathetic imbalance that can occur after TKA. It is followed by local skin changes such as sweat, temperature, edema and vascularization. It can lead to knee stiffness and is often treated with blockage to enable kinesiotherapy [19-21].

\section{Pseudoaneurysm}

Pseudoaneurysm is a rare complication after TKA but should never be forgotten as a cause of pain. The pseudoaneurysm of the genicular arteries can produce bleeding that will lead to hemolytic synovitis. The diagnosis is made by palpation of pulsatile masses, bloody aspiration of the joint and color Doppler ultrasonography. Treatment of pseudoaneurysm can be performed with surgical repair or percutaneous embolization [22-25].

\section{Anterior Knee Pain}

Anterior knee pain is one of the most common causes of persistent problems after implantation of the prosthesis. It may occur in cases where patellar resurfacing has or have not been performed. The incidence of anterior knee pain after TKA is $8 \%$ [26]. The need of performing patellar resurfacing is still a great discussion in the literature. On the one hand, resurfacing can lead to complications such as aseptic loosening, lateral facet syndrome, patellar fracture and overstuffing. On the other hand, failure to perform resurfacing of the patella can lead to chondrolysis and progression of patellar arthrosis. In cases of anterior knee pain when resurfacing of the patella is not performed, revision surgery for resurfacing has low success rates, and extra-articular causes should always be considered [27]. Anterior knee pain has to be carefully considered in cases of recent surgeries, since the natural tendency is spontaneous pain reduction in one year [28] 
and some non-modifiable predictors include female gender, severe preoperative pain, low pain threshold, young age and severe preoperative arthritis $[29,30]$. The modifiable predictors are anxiety, depression and problems in pain processing. Patients with increased postoperative pain tend to have an increased value on the pain catastrophizing scale (PCS) [31-33].

\section{Neurophysiology of Patellofemoral Pain}

Different causes for anterior pain may be considered, however the main cause is the insertional pain of the extensor apparatus [34-37]. Patients with anterior knee pain have a higher density of nociceptors in the lateral retinaculum, and a higher incidence of mechanical disorders in the patellofemoral joint. These disorders are instability, increased pressure in the sagittal plane and poor alignment of the extensor apparatus. Several causes for these disorders may occur, such as component position error, valgus alignment, and instability. Valgus alignment may be caused by muscle imbalance (dynamic valgus) or poor component positioning. Patellar tenosynovitis, synovitis, inflammatory processes of the Hoffa's fat pad and bone edema may also cause anterior knee pain. Van Jonbergen demonstrated a significant improvement in pain after TKA with synovectomy [38-40]. Also, avascular necrosis and patellar fracture may cause anterior pain, as well as the advancement of patellofemoral arthritis, the "patella baja" which is a shortening of the patellar tendon, and the offset error of the femoral component, which increases the patellar femoral pressure [41]. Functional pain often occurs in patients after TKA, since osteoarthritis leads to a weakness of the quadriceps. In addition, usually these patients also have fragility of the adductor and abductor muscles of the hip, and even with a good alignment of the prosthesis, a functional valgus can occur, causing instability in the extensor apparatus. In these cases, the strategy of treating pain with ultrasound guided blockage is used, as it will be shown later, to allow the patient to begin kinesiotherapy to correct fragility and muscle imbalance [42-46].

\section{Other Causes of Pain}

Other causes of residual pain after TKA are cutaneous neuromas, tendinitis, periarticular bursitis, root compression of the sciatic nerve, and hip osteoarthritis. The diagnosis of incisional neuroma is performed by the examination of the scar, with palpation and provocation of the symptom. We usually use ultrasound-guided blockages in the treatment of neuroma [47]. Peri-articular bursitis and tendinitis are diagnosed by palpatory physical examination and ultrasonographic confirmation. Physiotherapeutic treatment is generally effective, and ultrasound-guided injections of Hyaluronic Acid and Growth Factors may assist as treatment adjuncts $[48,49]$. The diagnosis of residual pain after TKA should be extended to the ipsilateral hip and lumbar sacral column, which are frequent causes of knee pain.

\section{Nonoperative Treatment}

Once the eminently surgical indications are excluded, the nonoperative treatment is carried out. The goal of this treatment is to decrease pain and improve knee function. The functional causes are treated preferably with exercises. A systematic review has shown that kinesiotherapy should not only focus on strengthening the quadriceps, but also stabilizing the hip and trunk. Other evidence shows a positive effect on knee brace use that stabilizes the patella in cases of anterior pain. In conclusion, the gain of the knee arch and the improvement of the function and the stabilization of the joint for the perfect functioning of the musculature will always be the best way for the treatment of residual pain after TKA. However, for effective kinesiotherapy, adjuvant drug therapy or ultrasoundguided blockages is often necessary [50-53].

\section{Joint and Periarticular Injections}

The treatment of residual pain after TKA with joint injections, mainly with corticosteroids, has become a usual practice, mainly after the advances of this technique with the aid of ultrasound. Also, it is a common practice to use other substances, like hyaluronic acid, platelet rich plasma, ketorolac and other analgesics. In the case of an already installed prosthesis, any discussion about potential damages caused by the drug due to chondrotoxicity is lost, but it must be noted that the synovium continues to deserve attention and its homeostasis is necessary for the proper functioning of the knee. Corticoid is an inhibitor of the endogenous production of hyaluronic acid, while hyaluronic acid and platelet rich plasma have the property of decreasing synovitis and increasing the production of endogenous glycosaminoglycans to restore synovial liquid [54,55]. Patients with residual pain after TKA have high levels of P-substance in the synovial fluid. Botulinum toxin, which is a neurotoxin, has high affinity for cholinergic synapses, causing a blockage in the release of acetylcholine from these nerve terminals, without altering the electrical conduction signals and/or the synthesis and storage of acetylcholine. Jasvinder found significant improvement in pain and knee function with residual pain after TKA with botulinum toxin joint injections and found no side effects in the 6 months period of study [56]. The major concern in joint injections is infection. While studying the risk of infections in corticosteroid injections in knees with pre-existing prostheses, Mills found a risk of 1 infection per 625 injections [57]. The indication of joint injections may take place in selected cases, when the suspicion of infection already exists and the aspiration of the inflammatory fluid is programmed, or in cases of rebellious synovitis to all other proposed treatments and where there is already the indication of synovectomy. Even so, the patient should be advised of the risk of infection.

Periarticular injections are generally used to control immediate postoperative pain, so the opioid administration can be decreased [58-60]. The great advantage of periarticular injection is to reduce pain, minimizing side effects and facilitating rehabilitation, total load and improvement of joint function $[61,62]$. Drugs used in periarticular injection are anesthetics, non-steroidal anti-inflammatories, corticosteroids, platelet rich plasma and hyaluronic acid $[62,63]$. The use of corticoid is still controversial as a drug for periarticular injection, although it has a potent antiinflammatory and antiemetic action, it may increase the chances of infection and cutaneous atrophy. Different cocktails are currently 
used and tested, such as ropivacaine and epinephrine, or clonidine, ketorolac, but the differences between them are questionable. The most used cocktail is the combination of ropivacaine, morphine and ketorolac, which act synergistically, without the addition of corticosteroids [64]. Botulinum toxin is also used in periarticular injections, especially in cases of flexion contracture [65]. Muchedzi conducted a systematic review of the use of periarticular injection of Platelet Rich Plasma (PRP) in TKA and concluded that in the short and medium terms, patients who used PRP achieved benefits in terms of pain improvement. Li performed a meta-analysis with 1,316 patients who received periarticular injections after TKA and concluded that the use of PRP is associated with an increase in the short- and long-term joint movement, and also a decrease in pain, without increasing the occurrence of infections [66].

\section{Peripheral Nerve Blocks}

Peripheral Nerve Blocks (PNB) have been considered an excellent technique for postoperative analgesia, but some questions are still under discussion, such as decreased motor function, risk of falls, risk of infection and neurological complications [67]. With the use of ultrasound as a guide for PNB techniques, the success of the procedures increased considerably, and the complications were minimized [68]. The current literature is not yet consensual as to the best technique indication for PNB, but there is a general agreement that the best results occur with ultrasound-guided injections. Femoral Nerve Block (FNB) is still the gold standard technique in control of TKA postoperative pain. FNB showed to be superior to analgesia caused by protocols with opioid use. When compared to epidural analgesia, FNB is similar as far as analgesic capacity, causing less vomiting, nausea and greater patient satisfaction [68]. Continuous FNB may weaken the quadriceps, increase the risk of falls and infections. It is still debatable whether continuous block is necessary, and some studies do not demonstrate superiority of continuous block versus single block. Moreover, a recent study indicates that blockages of peripheral nerves do not necessarily increase the probability of falls [69]. In cases of FNB insufficiency, blockage of the sciatic nerve can be suggested, but this indication is still controversial, due to the risk of nerve damage and muscle weakness $[70,71]$.

Adductor Canal Blockage (ACB) is a procedure capable of blocking the sensory branches of the knee, without the disadvantage of causing motor blockade of the quadriceps [72]. However, the literature shows some controversy as whether ACB is superior to FNB. Wang and Albrecht have shown that the complications of the two techniques are similar and rare $[73,74]$. Genicular Nerve Blocks (GNB) are a good alternative for the treatment of residual pain after TKA. Access to genicular nerves began for radio frequency procedures, as well as those guided by fluoroscopy. The literature is not yet consensual as whether radiofrequency is able to obtain better results than with anesthetic and corticoid blockade in terms of pain relief. However, the adverse effects of corticosteroids must be highlighted [75]. GNB can also be performed with the help of the ultrasound technique, and we do not yet know the superiority between techniques using fluoroscopy or ultrasound. However, the technique guided by ultrasound is simpler and does not use radiation $[76,77]$.

\section{Cryotherapy}

Application of ice in the knee with residual pain after TKA is still controversial in the literature as to its ability to decrease pain. Some studies show a great deal of effectiveness in improving pain, others show a few, and others shows no effectiveness at all. The mechanism of action of cryotherapy is based on decreasing local metabolism and enzymatic activity, including COX enzymes. It reduces nerve signaling, produces direct analgesia and decreases the development of hyperalgesia, induces vasoconstriction and reduces edema. Cryotherapy should be used with care to avoid damage to the skin $[78,79]$.

\section{Anticonvulsants}

Pregabalin acts on the calcium channel and was originally introduced in medical practice in 2004 as an anticonvulsant for the treatment of epilepsy. Engelman and Cateloy performed a metaanalysis of the efficacy and safety of Pregabalin on postoperative pain in 1,547 patients, concluding that Pregabalin is effective in improving pain, but it can cause dizziness and visual disturbances [80]. Pregabalin has been used for the treatment of chronic pain and may be used to treat residual TKA pain in patients who do not present side effects to the drug or risk of falls $[81,82]$.

\section{Duloxetine Hydrochloride}

Duloxetine is an inhibitor of serotonin and noradrenaline reception [83]. Theoretically, these actions should make it a good pain modulating agent [84]. Serotonin modulates the pro-nociceptive and anti- nociceptive effects in the central action of the brainstem. Noradrenaline has a predominantly anti- nociceptive effect. The balance between facilitation and depression of pain pathways is important for normal function. It decreases the absorption persistence of serotonin and the neurotransmission of monoamine that potentializes serotonin and noradrenaline in pathways of the descending inhibitory spine trat. Potentiation of serotonin and noradrenaline is necessary to produce effective analgesia. The action of drugs such as duloxetine on pain is independent of its effects on depression [85]. The onset of the pain benefit starts earlier than in depression. In addition, they have similar effects on pain in depressed and non-depressed people. Common side effects include nausea, headache, dry mouth, insomnia, constipation, dizziness, fatigue, drowsiness, hyperhidrosis and diarrhea [86].

These are mainly classified as mild to moderate and in the clinical setting appear less prevalent than the side effects with tricyclic antidepressants. In a systematic review of the Cochrane Institute, Lunn studied the efficacy and side effects of duloxetine for the treatment of diabetic neuropathy, fibromyalgia and chronic pain. The study comprised 12 studies with 2,728 patients and concluded 
that duloxetine at the dose of $60 \mathrm{mg}$ daily has moderate quality of evidence in the treatment of pain, but not in smaller dosages. As for the side effects, Lunn qualifies them as rare and small [87]. Although we do not yet have any literature with sufficient evidence regarding the treatment of residual pain in TKA, Wang conducted a Randomized Controlled Trail (RCT) for pain to study the efficacy of duloxetine $60 \mathrm{mg}$ with 407 patients who presented pain and knee or hip osteoarthritis. He concluded that at this dosage duloxetine is effective in the treatment of pain, safe and with low side effects [88-91].

\section{Author Preferred Method of Treating}

In the treatment of residual pain after TKA, it is very important to discard the causes of pain that are eminently surgical. In some cases, as in infections, the time between diagnosis and treatment should be as short as possible due to the risk of worsening local and clinics conditions of the patient. Initially, we should treat patient comorbidities that are extremely common, such as diabetes, hypothyroidism, depression, obesity and others. Once the surgical causes are ruled out, we move on to the nonoperative treatment, which aims to minimize the pain, so that the patient will be able to perform rehabilitation, which is essential for therapeutic success. The use of pain medications should be carefully indicated, and duloxetine at a dose of $60 \mathrm{mg}$ daily is very effective, especially for patients with associated depression. However, even non-depressed patients may benefit from this drug. The combination with Pregabalin may be indicated in specific cases, but the patient and the family should be advised about the side effects, especially the risk of falls. In patients who cannot be monitored on the first days of use of Pregabalin, the indication of the drug is impaired and another methodology without the risk of falls should be implemented.

In skin or scarring lesions, platelet rich plasma and hyaluronic acid offer surprising results, improving the viscoelastic quality of the skin, or even in the treatment of infections, since PRP also has bactericidal properties. The applications should always be superficial or guided by ultrasound to maintain superficiality and to avoid the chance of infections [92,93]. In the case of neuromas, we can also use the technique of injection guided by ultrasound [94-96]. Joint injections should be avoided because of the increased chance of infection. Rarely, and only in very important synovitis, and that already have surgical indication, we can use ultrasoundguided joint injection techniques, and PRP and hyaluronic acid are the substances of choice. We routinely examine the hip and lumbar sacral column, and in the case of irradiated pain, we perform ultrasound-guided blockages and viscossuplementation.

\section{Conflict of Interest}

The authors declare that they have no conflict of interest.

\section{Acknowledgment}

All sources of support were provided and funded by CERT. We would like to thank CERT staff for technical assistance.

\section{References}

1. (2000) American College of Rheumatology Subcommittee on Osteoarthritis Guidelines. Recommendations for the medical management of osteoarthritis of the hip and knee: 2000 update. Arthritis Rheum 43(9): 1905-1915.

2. Zhang W, Nuki G, Moskowitz RW, Lohmander LS, Tugwell P, et al. (2010) OARSI recommendations for the management of hip and knee osteoarthritis: Part III. Changes in evidence following systematic cumulative update of research published through January 2009. Osteoarthritis Cartilage 18(4): 476-499.

3. Rozell JC, Courtney PM, Dattilo JR, Wu CH, Lee GC (2017) Late Complications Following Elective Primary Total Hip and Knee Arthroplasty: Who, When, and How? J Arthroplasty 32(3): 719-723.

4. Meftah M, Ranawat AS, Ranawat CS (2011) The natural history of anterior knee pain in 2 posterior- stabilized, modular total knee arthroplasty designs. J Arthroplasty 26(8): 1145-1148.

5. Ranawat AS, Ranawat CS, Slamin JE, Dennis DA (2006) Patellar crepitation in the P.F.C. sigma total knee system. Orthopedics 29(suppl 9): S68-S70.

6. Caroline N Park, Peter B, White BA, Morteza Meftah (2016) Diagnostic Algorithm for Residual Pain After Total Knee Arthroplasty. Orthopedics 39(2): 246-252.

7. Knutson K, Lewold S, Robertsson O, Lidgren L (1994) The Swedish knee arthroplasty register: A nation-wide study of 30,003 knees 1976-1992. Acta Orthop Scand 65: 375-386.

8. Sharkey PF, Hozack WJ, Rothman RH, Shastri S, Jacoby SM (2002) Insall Award paper. Why are total knee arthroplasties failing today? Clin Orthop Relat Res 404: 7-13.

9. Mont MA, Serna FK, Krackow KA, Hungerford DS (1996) Exploration of radiographically normal total knee replacements for unexplained pain. Clin Orthop Relat Res 331: 216-220.

10. Sharkey PF, Hozack WJ, Rothman RH, Shastri S, Jacoby SM (2002) Insall Award paper. Why are total knee arthroplasties failing today? Clin Orthop Relat Res 404: 7-13.

11. Carulli C, Villano M, Bucciarelli G, Martini C, Innocenti M (2011) Painful knee arthroplasty: definition and overview. Clin Cases Miner Bone Metab 8(2): 23-25.

12. Basketter DA, Briatico Vangosa G, Kaestner W, Lally C, Bontick WJ (1996) Nickel, Cobalt and Chromium in consumer products: a role in allergic contact dermatitis? Contact Dermatitis 28: 15-25.

13. Mc Kenzie AW, Aitken CV, Ridsdill Smith R (1967) Urticaria after insertion of Smith-Petersen Vitallium nail. Br Med J 5570: 36.

14. Granchi D, Cenni E, Tignai D, Trisolino G, Baldini N, et al. (2008) Sensitivity to implant materials in patients with total knee arthroplasty. Biomaterials 29: 1494-1500.

15. Swiontkowsky MF, Agel J, Schwappach J, Mc Nair P, Welch M (2001) Cutaneous metal sensitivity in patients with orthopaedic injuries. J Orthop Trauma 2: 86-89.

16. Li AE, Sneag DB, Greditzer HG, Johnson CC, Miller TT, et al. (2016) Total Knee arthroplasty: Diagnostic Accuracy of Patterns of Synovitis at MR Imaging. Radiology 281(2): 499-506.

17. Li AE, Johnson CC, Sneag DB, Koch CN, Fields K, et al. (2017) Frondlike Synovitis on MRI and Correlation with Polyethylene Surface Damage of Total Knee Arthroplasty. AJR Am J Roentgenol.

18. Gwo Chin Lee MD, Paul A Lotke (2014) Does Chondrocalcinosis Affect Knee Society Scores and Range of Motion After TKA? Clin Orthop Relat Res 472: 1512-1517.

19. Burns AW, Parker DA, Coolican MR, Rajaratnam K (2006) Complex regional pain syndrome complicating total knee arthroplasty. J Orthop Surg (Hong Kong) 14(3): 280-283. 
20. Merksey H, Boduk N (1994) Classification of Chronic Pain: Descriptions of Chronic Pain Syndromes and Definitions of Pain Terms. ( $2^{\text {nd }}$ edn.) Seattle, IASP Press, Washington, USA.

21. O Connell NE, Wand BM, Mc Auley J, Marston L, Moseley GL (2013) Interventions for treating pain and disability in adults with complex regional pain syndrome. Cochrane Database Syst Rev 30(4): CD009416.

22. Julien TP, Gravereaux E, Martin S (2012) Superior medial geniculate artery pseudoaneurysm after primary total knee arthroplasty. J Arthroplasty 27(2): e13-e16.

23. Shin YS, Hwang YG, Savale AP, Han SB (2014) Popliteal artery pseudoaneurysm following primary total knee arthroplasty. Knee Surg Relat Res 26(2): 117-120.

24. Boutchichi A, Ciornohac J, Daubresse F (2013) Pseudoaneurysm after total knee arthroplasty: a rare complication with different possible clinical presentations. Acta Orthop Belg 79(1): 16-19.

25. Page CP, Curtis M, Sutter MC, Walker M, Hoffman B (2002) Integrated Pharmacology. Mosby, London, UK.

26. Sensi L, Buzzi R, Giron F, De Luca L, Aglietti P (2011) Patellofemoral function after total knee arthroplasty: gender-related differences. Arthroplasty 26(8): 1475-1480.

27. Ghosh KM, Merican AM, Iranpour F, Deehan DJ, Amis AA (2009) The effect of overstuffing the patellofemoral joint on the extensor retinaculum of the knee. Knee Surg Sports Traumatol Arthrosc 17(10): 1211-1216.

28. Forsythe ME, Dunbar MJ, Hennigar AW, Sullivan MJ, Gross M (2008) Prospective relation between catastrophizing and residual pain following knee arthroplasty: two-year follow-up. Pain Res Manag 13(4): 335-341.

29. Bonnin MP, Basiglini L, Archbold HA (2011) What are the factors of residual pain after uncomplicated TKA? Knee Surg Sports Traumatol Arthrosc 19(9): 1411-1417.

30. Liu SS, Buvanendran A, Rathmell JP, Sawhney M, Bae JJ, et al. (2012) Predictors for moderate to severe acute postoperative pain after total hip and knee replacement. Int Orthop 36(11): 2261-2267.

31. Forsythe ME, Dunbar MJ, Hennigar AW, Sullivan MJ, Gross M (2008) Prospective relation between catastrophizing and residual pain following knee arthroplasty: two-year follow-up. Pain Res Manag 13(4): 335-341.

32. Brander VA, Stulberg SD, Adams AD, Harden RN, Bruehl S, et al. (2003) Predicting total knee replacement pain: a prospective, observational study. Clin Orthop 416: 27-36.

33. Schnurr C, Jarrous M, Güdden I, Eysel P, König DP (2013) Preoperative arthritis severity as a predictor for total knee arthroplasty patients'satisfaction. Int Orthop 37(7): 1257-1261.

34. Sanchis Alfonso V, Roselló Sastre E, Monteagudo Castro C, Esquerdo (1998) Quantitative analysis of nerve changes in the lateral retinaculum in patients with isolated symptomatic patellofemoral malalignment. A preliminary study. Am J Sports Med 26(5): 703-709.

35. Petersen W, Rembitzki IV, Brüggemann GP, Ellermann A, Best R, et al. (2014) Anterior knee pain after total knee arthroplasty: a narrative review. Int Orthop 38(2): 319-328.

36. Sanchis Alfonso V, Roselló Sastre E (2000) Immunohistochemical analysis for neural markers of the lateral retinaculum in patients with isolated symptomatic patellofemoral malalignment. A neuroanatomic basis for anterior knee pain in the active young patient. Am J Sports Med 28(5): 725-731.

37. Sanchis Alfonso V (2008) Patellofemoral pain. Orthopade 37(9): 835836.

38. Van Jonbergen HP, Reuver JM, Mutsaerts EL, Poolman RW (2014) Determinants of anterior knee pain following to talk knee replacement: a systematic review. Knee Surg Sports Traumatol Arthrosc PMID: 23160846.
39. Myer GD, Ford KR, Barber Foss KD, Goodman A, Ceasar A, et al. (2010) The incidence and potential pathomechanics of patellofemoral pain in female athletes. Clin Biomech. 25(7): 700-707.

40. Petersen W, Ellermann A, Liebau C, Brüggemann GP, Best R, et al. (2010) Das patellofemorale Schmerzsyndrom. Orthop Prax 46(8): 34-42.

41. Malo M, Vince KG (2003) The unstable patella after total knee arthroplasty: etiology, prevention, and management. J Am Acad Orthop Surg 11: 364-371.

42. Scuderi GR, Insall JN, Scott NW (1994) Patellofemoral pain after total knee arthroplasty. J Am Acad Orthop Surg 2: 239-246.

43. Lin F, Wilson NA, Makhsous M, Press JM, Koh JL, et al. (2010) In vivo patellar tracking induced by individual quadriceps components in individuals with patellofemoral pain. J Biomech 43(2): 235-241.

44. Mizner RL, Petterson SC, Snyder Mackler L (2005) Quadriceps strength and the time course of functional recovery after total knee arthroplasty. J Orthop Sports Phys Ther 35: 424-436.

45. Mizner RL, Petterson SC, Stevens JE, Axe MJ, Snyder Mackler L (2005) Preoperative quadriceps strength predicts functional ability one year after total knee arthroplasty. J Rheumatol 32: 1533-1539.

46. Mizner RL, Snyder Mackler L (2005) Altered loading during walking and sit-to-stand is affected by quadriceps weakness after total knee arthroplasty. J Orthop Res 23: 1083-1090.

47. Kesikburun S, Köroğlu Omaç Ö, Yaşar E, Yilmaz B, Kenan Tan A (2014) Ultrasound guided block of the saphenous neuroma following use of an AFO in a patient with paraplegia. A case reports. Eur J Phys Rehabil Med 50(2): 197-198.

48. Leanne Dupley, Charalambous CP (2017) Charalambous, Platelet-Rich Plasma Injections as a Treatment for Refractory Patellar Tendinosis: A Meta-Analysis of Randomised Trials. Knee Surg Relat Res 29(3): 165171.

49. Kumai T, Muneta T, Tsuchiya A, Shiraishi M, Ishizaki Y, et al. (2014) The short-term effect after a single injection of high-molecular-weight hyaluronic acid in patients with enthesopathies (lateral epicondylitis, patellar tendinopathy, insertional Achilles tendinopathy, and plantar fasciitis): a preliminary study. J Orthop Sci 19(4): 603-611.

50. Harvie D, OLeary T, Kumar S (2011) A systematic review of randomized controlled trials on exercise parameters in the treatment of patellofemoral pain: what works? J Multidiscip Healthc 4: 383- 392.

51. Gelfer Y, Pinkas L, Horne T, Halperin N, Alk D (2003) Symptomatic transient patellar ischemia following total knee replacement as detected by scintigraphy. A prospective, randomized, double blind study comparing the mid-vastus to the medial para-patellar approach. Knee 10: $341-345$.

52. Nakagawa T, Muniz T, Baldon Rde M, Dias Maciel C, De Menezes Reiff RB (2008) The effect of additional strengthening of hip abductor and lateral rotator muscles in patellofemoral pain syndrome: a randomised controlled pilot study. Clin Rehabil 22(12): 1051-1060.

53. Warden SJ, Hinman RS, Watson MA, Avin KG, Bialocerkowski AE, et al. (2008) Patellar taping and bracing for the treatment of chronic knee pain: a systematic review and meta-analysis. Arthritis Rheum 59(1): 73 83.

54. Sakata R, Mc Nary SM, Miyatake K, Lee CA, Van Den Bogaerde JM, et al. (2015) Stimulation of the Superficial Zone Protein and Lubrication in the Articular Cartilage by Human Platelet-Rich Plasma. Am J Sports Med 43(6): 1467-1473.

55. Maheu E, Rannou F, Reginster JY (2016) Efficacy and safety of hyaluronic acid in the management of osteoarthritis: Evidence from real-life setting trials and surveys. Semin Arthritis Rheum 45(4 Suppl): S28-33.

56. Singh JA, Mahowald ML, Noorbaloochi S (2010) Intraarticular Botulinum Toxin A for Refractory Painful Total Knee Arthroplasty: A Randomized Controlled Trial. J Rheumatol 37(11): 2377-2386. 
57. Mills ES, Elman MB, Foran JRH (2017) The Risk of Acute Infection Following Intra-articular Corticosteroid Injection into a Preexisting Total Knee Arthroplasty. J Arthroplasty 33(1): 216-219.

58. Busch CA, Shore BJ, Bhandari R, Ganapathy S, Mac Donald SJ, et al. (2006) Efficacy of periarticular multimodal drug injection in total knee arthroplasty. A randomized trial. J Bone Joint Surg Am 88: 959-963.

59. Affas F, Nygards EB, Stiller CO, Wretenberg P, Olofsson C (2011) Pain control after total knee arthroplasty: a randomized trial comparing local infiltration anesthesia and continuous femoral block. Acta Orthop 82: 441-447.

60. Mauerhan DR, Campbell M, Miller JS, Mokris JG, Gregory A, (1997) Intraarticular morphine and/or bupivacaine in the management of pain after total knee arthroplasty. J Arthroplasty 12: 546-552.

61. Kelley TC, Adams MJ, Mulliken BD, Dalury DF (2013) Efficacy of multimodal perioperative analgesia protocol with periarticular medication injection in total knee arthroplasty: a randomized, doubleblinded study. J Arthroplasty 28: 1274-1277.

62. Maheshwari AV, Blum YC, Shekhar L, Ranawat AS, Ranawat CS (2009) Multimodal pain management after total hip and knee arthroplasty at the Ranawat Orthopaedic Center. Clin Orthop Relat Res 467: 1418-1423.

63. Tsukada S, Wakui M, Hoshino A (2016) The impact of including corticosteroid in a periarticular injection for pain control after total knee arthroplasty: a double blind randomised controlled trial. Bone Joint J 98(1): 194-200.

64. Kim TW, Park SJ, Lim SH, Seong SC, Lee S, et al. (2015) Which analgesic mixture is appropriate for periarticular injection after total knee arthroplasty? Prospective, randomized, double blind study. Knee Surg Sports Traumatol Arthrosc 23(4): 838-845.

65. Smith EB, Shafi KA, Greis AC, Maltenfort MG, Chen AF (2016) Decreased flexion contracture after total knee arthroplasty using Botulinum toxin A: a randomized controlled trial. Knee Surg Sports Traumatol Arthrosc 24(10): 3229-3234.

66. Muchedzi TA, Roberts SB (2018) A systematic review of the effects of platelet rich plasma on outcomes for patients with knee osteoarthritis and following total knee arthroplasty. Surgeon 16(4): 250-258.

67. Bauer MC, Pogatzki Zahn EM, Zahn PK (2014) Regional analgesia techniques for total knee replacement. Curr Opin Anaesthesiol 27(5): 501-506.

68. Chan EY, Fransen M, Parker DA, Assam PN, Chua N (2014) Femoral nerve blocks for acute postoperative pain after knee replacement surgery. Cochrane Database Syst Rev (5): CD009941.

69. Memtsoudis SG, Danninger T, Rasul R, Poeran J, Gerner P, et al. (2014) Inpatient falls after total knee arthroplasty: the role of anesthesia type and peripheral nerve blocks. Anesthesiology 120: 551-563.

70. Abdallah FW, Brull R (2011) Is sciatic nerve block advantageous when combined with femoral nerve block for postoperative analgesia following total knee arthroplasty? A systematic review. Reg Anesth Pain Med 36(5): 493-498.

71. Wegener JT, Van Ooij B, Van Dijk CN, Hollmann MW, Preckel B, et al. (2011) Value of singleinjection or continuous sciatic nerve block in addition to a continuous femoral nerve block in patients undergoing total knee arthroplasty: a prospective, randomized, controlled trial. Reg Anesth Pain Med 36: 481-488.

72. Bauer MC, Pogatzki Zahn EM, Zahn PK (2014) Regional analgesia techniques for total knee replacement. Curr Opin Anaesthesiol 27(5): 501-506.

73. Wang C, Cai XZ, Yan SG (2015) Comparison of periarticular multimodal drug injection and femoral nerve block for postoperative pain management in total knee arthroplasty: a systematic review and metaanalysis. J Arthroplasty 30: 1281-1286.

74. Albrecht E, Guyen O, Jacot Guillarmod A, Kirkham KR (2016) The analgesic efficacy of local infiltration analgesia vs femoral nerve block after total knee arthroplasty: a systematic review and meta analysis. $\mathrm{Br}$ J Anaesth 116(6): 597-609.

75. Qudsi Sinclair S, Borrás Rubio E, Abellan Guillén JF, Padilla Del Rey ML, Ruiz Merino G (2017) Comparison of Genicular Nerve Treatment Using Either Radiofrequency or Analgesic Block with Corticosteroid for Pain after a Total Knee Arthroplasty: A Double-Blind, Randomized Clinical Study. Pain Pract 17(5): 578-588.

76. González Sotelo V, Maculé F, Minguell J, Bergé R, Franco C, et al. (2017) Ultrasound- guided genicular nerve block for pain control after total knee replacement: Preliminary case series and technical note. Rev Esp Anestesiol Reanim 64(10): 568-576.

77. Yasar E, Kesikburun S, Kılıç C, Güzelküçük Ü, Yazar F (2015) Accuracy of Ultrasound-Guided Genicular Nerve Block: A Cadaveric Study Pain Physician 18(5): E899-E904.

78. Gibbons CE, Solan MC, Ricketts DM (2001) Cryotherapy compared with Robert Jones bandage after total knee replacement: a prospective randomized trial. Int Orthop 25(4): 250-252.

79. Healy WL, Seidman J, Pfeifer BA (1994) Cold compressive dressing after total knee arthroplasty. Clin Orthop Relat Res (299): 143-146.

80. Engelman E, Cateloy F (2011) Efficacy and safety of perioperative pregabalin for post-operative pain: a meta-analysis of randomizedcontrolled trials. Acta Anaesthesiol Scand 55(8): 927-943.

81. Bhusal S, Diomampo, S, Magrey MN (2016) Clinical utility, safety, and efficacy of pregabalin in the treatment of fibromyalgia. Drug Healthc Patient Saf 8: 13-23.

82. Mathieson S, Maher CG, Mc Lachlan AJ, Latimer J, Koes BW, et al. (2013) PRECISE - Pregabalin in addition to usual care for sciatica: study protocol for a randomised controlled trial. Trials 14: 213.

83. Scheussler B (2006) What do we know about duloxetine's mode of action? Evidence from animals to humans. BJOG 113(Suppl 1): 5-9.

84. Bymaster FP, Dreshfield Ahmad LJ, Threlkeld PG, Shaw JL, Thompson $\mathrm{L}$, et al. (2001) Comparative affinity of duloxetine and venlafaxine for serotonin and norepinephrine transporters in vitro and in vivo, human serotonin receptor subtypes, and other neuronal receptors. Neuropsychopharmacology 25(6): 871-880.

85. Perahia DG, Pritchett YL, Desaiah D, Raskin J (2006) Efficacy of duloxetine in painful symptoms: analgesic or antidepressant effect? International Clinical Psychopharmacology 21(6): 311-317.

86. Gahimer J, Wernicke J, Yalcin I, Ossanna MJ, Wulster Radcliffe M, et al. (2007) A retrospective polled analysis of duloxetine safety in 23,983 subjects. Current Medical Research Opinion 23(1): 175-84

87. Lunn MP, Hughes RA, Wiffen PJ (2014) Duloxetine for treating painful neuropathy, chronic pain or fibromyalgia. Cochrane Database Systematic Review (1): CD007115.

88. Wang, Skljarevski V (2017) Efficacy and safety of duloxetine in Chinese patients with chronic pain due to osteoarthritis: a randomized, doubleblind, placebo-controlled study. Osteoarthritis Research Society International.

89. Yucel, Evren (2013) Ilioinguinal-iliohypogastric nerve block with intravenous dexketoprofen improves postoperative analgesia in abdominal hysterectomies. Rev Bras Anestesiol 63(4): 334-339.

90. Vishwanatha S, Kalappa S (2017) Continuous femoral nerve blockade versus epidural analgesia for postoperative pain relief in knee surgeries: A randomized controlled study. Anesth Essays Res 11: 599-605.

91. Peng K, Zhang J, Chen WR, Liu HY, Ji FH (2017) Ultrasound-Guided Stellate Ganglion Block Improves Gastrointestinal Function After Thoracolumbar Spinal Surgery. Clin Ther (11): 2322-2330.

92. Ulusal BG (2017) Platelet-rich plasma and hyaluronic acid - an efficient biostimulation method for face rejuvenation. J Cosmet Dermatol (1): 112-119. 
93. Gonchar IV, Lipunov AR, Afanasov IM, Larina NA, Faller AP, et al. (2017) Platelet rich plasma and growth factors cocktails for diabetic foot ulcers treatment: state of art developments and future prospects. Diabetes \& Metabolic Syndrome: Diabetes Metab Syndr (17): 30294-302111.

\section{ISSN: 2574-1241}

DOI: 10.26717/BJSTR.2019.22.003746

Breno Pazinatto Antonio. Biomed J Sci \& Tech Res

(c) (P) This work is licensed under Creative

Submission Link: https://biomedres.us/submit-manuscript.php
94. Strakowski JA (2016) Ultrasound-Guided Peripheral Nerve Procedures. Phys Med Rehabil Clin N Am. 27(3): 687-715.

$\begin{array}{ll}\text { BIOMEDICAL } & \text { Assets of Publishing with us } \\ \text { RESEARCHES } & \text { - Global archiving of articles } \\ \text { - Immediate, unrestricted online access } & \text { - Rigorous Peer Review Process } \\ & \text { - Authors Retain Copyrights } \\ \end{array}$

